Provided for non-commercial research and education use. Not for reproduction, distribution or commercial use.

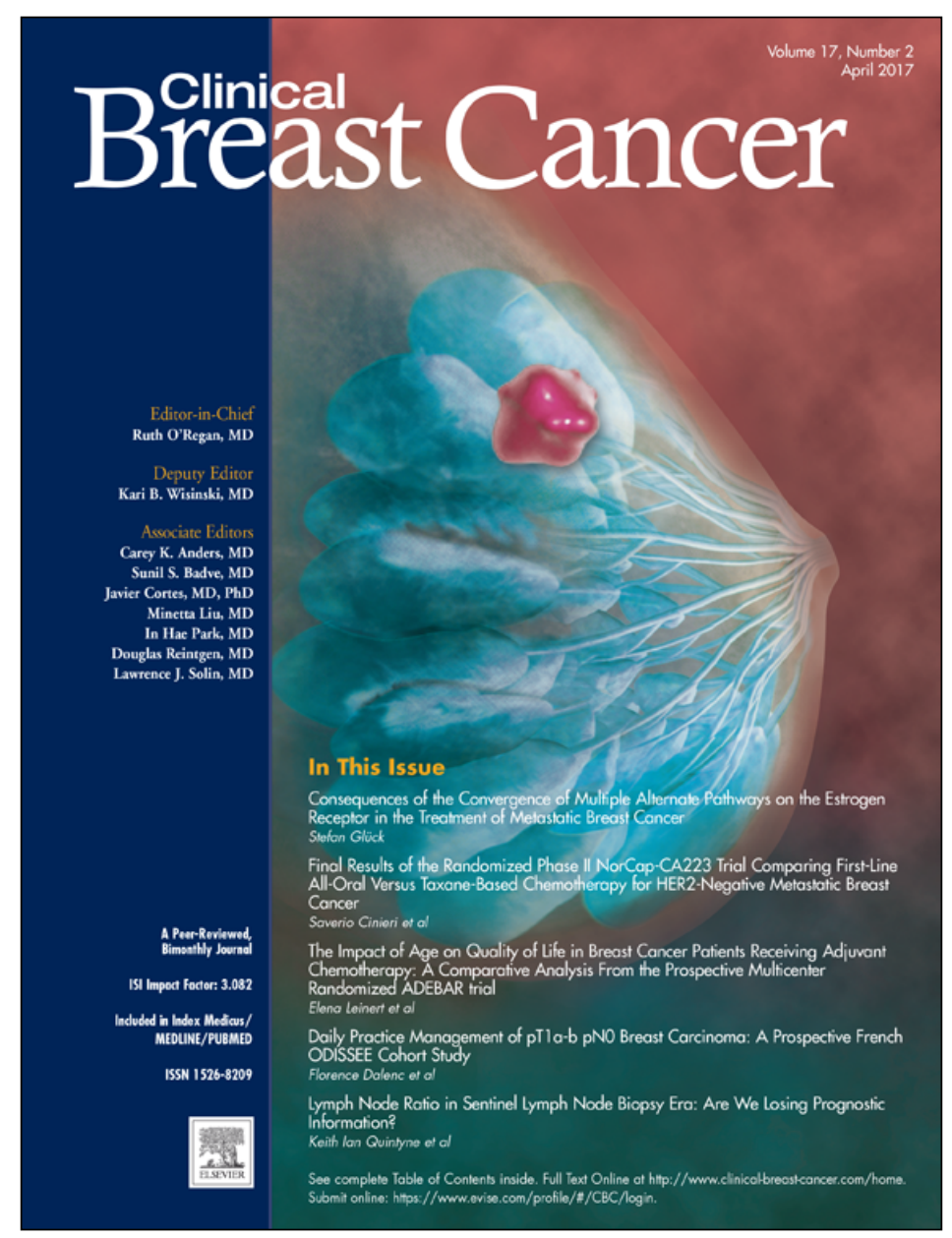

This article appeared in a journal published by Elsevier. The attached copy is furnished to the author for internal non-commercial research and education use, including for instruction at the author's institution and sharing with colleagues.

Other uses, including reproduction and distribution, or selling or licensing copies, or posting to personal, institutional or third party websites are prohibited.

In most cases authors are permitted to post their version of the article (e.g. in Word or Tex form) to their personal website or institutional repository. Authors requiring further information regarding Elsevier's archiving and manuscript policies are encouraged to visit:

http://www.elsevier.com/authorsrights 


\title{
Does Conservative Surgery for Breast Carcinoma Still Require Axillary Lymph Node Evaluation? A Retrospective Analysis of 1156 Consecutive Women With Early Breast Cancer
}

\author{
Antonio Marrazzo, ${ }^{1,2}$ Giuseppe Damiano, ${ }^{1}$ Pietra Taormina, ${ }^{2}$ Salvatore Buscemi, ${ }^{1}$ \\ Attilio Ignazio Lo Monte, ${ }^{1}$ Emilia Marrazzo ${ }^{3}$
}

\begin{abstract}
We performed a retrospective analysis of 1156 patients affected by early breast cancer in order to estimate the real incidence of patients with T1 tumors presenting $>2$ metastatic lymph nodes. The advantage of axillary surgery seems to be limited only to a specific subgroup of $\mathrm{T} 1$ patients who are undergoing conservative surgery plus radiotherapy.

Background: The role of axillary surgery for early breast carcinoma treated with conservative surgery and radiotherapy is currently the subject of considerable investigation. Recent studies have supported the noninferiority of avoiding axillary surgery in terms of overall survival when sentinel lymph node biopsy (SLNB) presents $\leq 2$ positive lymph nodes, thus sparing the patients from complications. There are some ongoing studies investigating the possibility of omitting SLNB. Axillary study seems to be sufficiently replaced by SLNB for staging the disease. Axillary surgery maintains a therapeutic role in the presence of $>2$ metastatic lymph nodes at SLNB. Patients and Methods: We performed a retrospective analysis of 1156 patients with early breast cancer to estimate the real incidence of patients with T1 tumors presenting $>2$ metastatic lymph nodes. Results: Of the 1156 cases, only $106(9.2 \%)$ had $>2$ axillary metastatic lymph nodes. More specifically, $38(4.3 \%)$ of $884 \mathrm{~T} 1$ cases, and $6(2.3 \%)$ of 257 of T1b cases had $>2$ metastatic lymph nodes. Conclusion: The advantage of axillary surgery seems to be limited only to a specific subgroup of $\mathrm{T} 1$ patients who are undergoing conservative surgery plus radiotherapy. The ongoing studies on avoiding SLNB will likely prove the noninferiority of omitting biopsy because these studies are conducted in the whole population of early breast cancers. It is necessary to identify more accurately the subpopulation of patients who may benefit from axillary surgery.
\end{abstract}

Clinical Breast Cancer, Vol. 17, No. 2, e53-7 @ 2016 Elsevier Inc. All rights reserved.

Keywords: Axillary lymph node dissection, More than two metastatic axillary lymph nodes, Not axillary surgery staging, Sentinel lymph node biopsy, T1 tumors

\section{Introduction}

The purpose of surgery for breast tumors is to improve overall survival as well as to achieve local control of the disease and maintain an acceptable quality of life. The current treatment of early

${ }^{1}$ Department of Surgical, Oncological and Stomatological Sciences, University of Palermo

${ }^{2}$ Breast Unit, Macchiarella Clinic, Palermo, Italy

${ }^{3}$ Breast Unit, Humanitas Research Hospital, Rozzano, Italy

Submitted: Jun 28, 2016; Revised: Sep 6, 2016; Accepted: Oct 12, 2016; Epub: Oct $18,2016$.

Address for correspondence: Antonio Marrazzo, M.D., Department of Surgical,

Oncological and Stomatological Sciences, University of Palermo, Via del Vespro, 129

90127 Palermo, Italy

E-mail contact: marrazzoantonio@libero.it breast carcinoma is based on conservative surgery tailored to the volume of disease in association with whole-breast radiotherapy and specific medical therapy. Sentinel lymph node biopsy (SLNB) provides information regarding the lymph node spreading of the tumor: if positive nodes are detected, the surgery is completed by axillary lymph node dissection (ALND).

Axillary surgery for breast cancer is currently considered a staging procedure that does not seem to influence breast cancer mortality, although SLNB alone provides sufficient information in the therapeutic setting. Moreover, ALND is burdened by complications that negatively affect quality of life.

Several studies have suggested that ALND could be an overtreatment, even in the case of positive sentinel lymph node (SLN). The American College of Surgeons Oncology Group (ACOSOG) 
Z0011 trial found that for clinically negative lymph node tumors (T1/T2 N0 M0) with SLN metastases in $\leq 2$ nodes, ALND can be safely avoided, and surgeons are still provided with adequate information to permit surgical staging and comparable locoregional control and survival. ${ }^{1}$

Another trial (International Breast Cancer Study Group [IBCSG] 23-01) $)^{2}$ conducted on patients with micrometastatic SLN positivity and tumor $<5 \mathrm{~cm}$ in size demonstrated the noninferiority of avoiding ALND, thus sparing the patient from the complications of axillary surgery. A randomized clinical trial by Agresti et $\mathrm{al}^{3}$ performed on T1N0 breast cancers supported the noninferiority, in selected groups of low-risk patients and in terms of overall survival, of breast-conservation surgery without ALND compared to breast conservation plus ALND. The 2014 American Society of Clinical Oncology and 2015 St Gallen 2015 guidelines now suggest that ALND may be omitted in selected patients with 1 to 2 positive SLNs who are undergoing conservative surgery and radiotherapy without affecting survival or risk of local recurrence. $^{4,5}$ The SOUND (Sentinel node vs. Observation after axillary Ultra-SouND) trial is currently ongoing to evaluate SLNB with or without ALND versus no axillary surgical staging. ${ }^{6}$ Also ongoing is the Intergroup-Sentinel-Mamma (INSEMA) trial, which is testing the noninferiority of no axillary surgery compared to SLNB.

Because avoiding ALND is to be considered safe when SLNB presents $\leq 2$ positive lymph nodes, the obvious question that arises is, how many patients who undergo conservative surgery have $>2$ metastatic axillary lymph nodes? This group of patients could possibly benefit from ALND given the absence of benefits when metastatic axillary lymph nodes are $\leq 2$.

The aim of this study was to retrospectively evaluate a population of patients with early breast cancer treated with a conservative approach to obtain cases of $>2$ metastatic axillary lymph nodes after ALND.

\section{Patients and Methods}

We retrospectively evaluated a cohort of 1156 consecutive women with early breast cancer ( 2 patients had bilateral carcinoma) between January 2001 and December 2013. All patients underwent breast-conserving surgery and SLNB; when the SLNB results were positive, axillary dissection was performed. After surgery, all patients were treated by external-beam radiotherapy on the whole breast through 2 tangential fields ( 50 plus 10 Gy as a boost to the tumor bed) with a linear accelerator. We evaluated the number and percentage of patients with positive SLN, patients with positive SLN treated with ALND, patients with negative axillary lymph nodes after ALND, and, globally, the percentage of patients with $>2$ metastatic axillary lymph nodes. According to the tumor, node, metastasis classification system, SLNs with micrometastasis were considered positive and SLNs with isolated tumor cells negative.

\section{Results}

The median age of patients was 57.2 years (range, 29-86 years). The average tumor diameter was $16 \mathrm{~mm}$, with a median of $15 \mathrm{~mm}$. Patient characteristics are summarized in Table 1. A total of 648 patients had SLN localization by radiocolloid, 248 by blue dye, and 262 by combined techniques, as previously reported. ${ }^{8,9}$ Of 1156
Table 1 Patient Characteristics

\begin{tabular}{l|c}
\hline Characteristic & Value \\
\hline Total No. of Cases & 1156 \\
\hline T1 & 884 \\
\hline T2 & 257 \\
\hline Median age (years) & $57.2(29-85)$ \\
\hline Mean Tumor Diameter & $16 \mathrm{~mm}$ \\
\hline G1 & $344(29.8 \%)$ \\
\hline G2 & $538(46.5 \%)$ \\
\hline G3 & $274(23.7 \%)$ \\
\hline ER & $584(85.1 \%)$ \\
\hline ER & \\
\hline ER ND & $146(12.6 \%)$ \\
\hline PR ${ }^{+}$ & $26(2.3 \%)$ \\
\hline PR & \\
\hline PR ND & $828(71.6 \%)$ \\
\hline HER-2 0 & $302(26.1 \%)$ \\
\hline HER-2 $1^{+}$ & $26(2.3 \%)$ \\
\hline HER-2 2 & $212(18.2 \%)$ \\
\hline HER-2/HER-2 $3^{+}$ & $553(47.9 \%)$ \\
\hline HER-2 ND & $226(19.6 \%)$ \\
\hline
\end{tabular}

Abbreviations: $E R=$ estrogen receptor; $G=$ grade; HER-2 = human epidermal growth factor receptor 2 ; $\mathrm{ND}=$ not determined; $\mathrm{PR}=$ progesterone receptor.

cases, 884 were of T1 disease and $272 \mathrm{~T} 2$ disease. SLNB results were negative in 770 cases (66.6\% of cases) and metastatic in 386 $(33.4 \%)$. Of the latter, in 283 cases $(24.5 \%)$ there was a macrometastasis and in 103 cases (8.9\%) a micrometastasis. A total of 380 of 386 patients with metastatic SLN underwent ALND; in 234 patients (61.6\%), the axilla results were negative. Overall, 274 patients had $\leq 2$ metastatic lymph nodes and 106 (9.2\%) had $>2$ metastatic lymph nodes (Table 2). Considering only the $884 \mathrm{~T} 1$ tumors (Table 2), SLNB results were negative in 650 cases $(73.5 \%)$ and metastatic in 234 (26.5\%); of these, 166 (18.8\%) were macrometastasis and $68(7.7 \%)$ micrometastasis. ALND was performed in 233 of 234 cases of positive SLNB; histology was negative for 166 cases $(71.3 \%)$. Therefore, only 38 (4.3\%) of $884 \mathrm{~T} 1$ patients had $>2$ axillary metastatic lymph nodes. Instead, SLNB results were negative in $199(77.4 \%)$ of $257 \mathrm{~T} 1 \mathrm{~b}$ patients, and metastatic disease occurred in 35 patients (13.6\%).

In 35 patients who underwent ALND, results were negative in 24 patients $(68.6 \%)$. In only $6(2.3 \%)$ of $257 \mathrm{~T} 1 \mathrm{~b}$ patients did the axilla contain $>2$ metastatic lymph nodes.

\section{Discussion}

If we accept the premise that axillary surgery offers a real advantage to patients who undergo conservative surgery and radiotherapy and who present with $>2$ metastatic axillary lymph nodes, then according to the data obtained from this unselected population, it emerges that the majority of $\mathrm{T} 1$ patients with positive SLNB results were overtreated by axillary surgery. Only $4.3 \%$ of T1 patients had $>2$ metastatic lymph nodes and thus obtained benefit from extending surgery to the axilla; this percentage decreased to $2.3 \%$ for T1b patients. The limitation is that these results come 
Table 2 Characteristics of Axillary Lymph Nodes

\begin{tabular}{|c|c|c|c|c|c|c|}
\hline Disease & SLN $^{-}$ & $\begin{array}{c}\text { SLN }^{+} \\
\text {Macrometastasis }\end{array}$ & $\begin{array}{c}\text { SLN }^{+} \\
\text {Micrometastasis }\end{array}$ & ALND $^{-}$ & $\mathrm{LN}^{+} \leq 2$ at ALND & $\mathrm{LN}^{+}>2$ at ALND \\
\hline Total $(n=1156)$ & $770(66.6 \%)$ & $283(24.48 \%)$ & $103(8.84 \%)$ & $234 / 380(61.6 \%)$ & $270(23.3 \%)$ & $106(9.2 \%)$ \\
\hline $\mathrm{T} 1(\mathrm{n}=884)$ & $650(73.5 \%)$ & $166(18.8 \%)$ & $68(7.7 \%)$ & 166/233 (71.5\%) & $194(22.2 \%)$ & $38(4.3 \%)$ \\
\hline $\operatorname{T1b}(n=257)$ & $199(74.4 \%)$ & $25(9.7 \%)$ & $10(3.9 \%)$ & $24 / 35(68.6 \%)$ & $29(11.3 \%)$ & $6(2.3 \%)$ \\
\hline
\end{tabular}

Abbreviations: ALND = axillary lymph node dissection; LN = lymph node; SLN = sentinel lymph node.

from an observational study based on historical data and not from a randomized population. Our results come from a single-center, single-surgical-team experience. The patients were not selected; some were symptomatic at the time of discovery of the disease, and some came to us as a result of cancer screening campaigns. This population therefore reflects the real incidence of disease in the general population. SLN evaluation still marks a watershed in the management of early breast carcinoma.

SLNB has resulted in an improvement in the quality of life of patients who undergo breast surgery by reducing the complications that may arise from nonselective axillary surgery. ${ }^{10}$ Initial contraindications, such as multifocal and multicentric tumor or previous excisional biopsy, have been eliminated. ${ }^{11,12}$ Furthermore, there is improved understanding regarding the lymphatic drainage of the breast into the axillary lymph nodes. The progression and metastatic spreading of tumor is now known to occur in a stepwise, continuous fashion from the periphery of the axilla in $97.4 \%$ of patients, and only in $2.6 \%$ of cases does it involve axillary level II, skipping axillary level I. ${ }^{13}$

The Axillary Lymphatic Mapping Against Nodal Axillary Clearance (ALMANAC) $\operatorname{trial}^{14}$ found that women who underwent SLNB alone experienced less lymphedema and sensory deficit than did women who underwent ALND. In addition, the women were also able to resume their normal daily activities more quickly than women who underwent ALND. ${ }^{15,16}$

Some criticisms had been leveled at the ACOSOG Z0011 trial resulting from the "favorable" nature of the disease in the enrolled randomized patients, where only $27 \%$ of the patients had additional metastatic nodes after ALND, compared to a higher percentage in other studies. Moreover, the younger population and those with estrogen receptor-negative tumors were insufficient in number to consider avoidance of ALND a safe prospect for this group. These criticisms, however, do not detract from the value of this landmark trial.

Dengel et $\mathrm{al},{ }^{17}$ in a prospective study designed to determine how often ALND can be avoided in patients meeting ACOSOG Z0011 eligibility criteria, reported that $84 \%$ of patients, not selected on the basis of age, tumor characteristics, axillary imaging, or nomogram predictions, were found to have metastases in $\leq 2$ axillary nodes, thus suggesting that these patients had a low axillary tumor burden.

The role of SLNB is currently under investigation, given the reduced information coming from the axillary status and as a result of the emerging role of tumor biology in the choice of tailored therapy. A randomized multicenter trial is underway in patients with a negative preoperative axillary assessment, tumor $\leq 2 \mathrm{~cm}$, and patients eligible for conservative surgery to evaluate SLNB with or without axillary dissection versus observation (no axillary surgical staging). ${ }^{6}$ The primary end point of the trial is disease-free survival. The results obtained from the preliminary analysis regarding the impact of different types of surgery on postoperative physical function and symptoms of the ipsilateral upper limb are that SLNB significantly worsens early postoperative physical function and symptoms of ipsilateral upper limb compared to no surgery of the axilla. This finding is limited to the first week after the operation and is no longer present at 6 and 12 months. ${ }^{18}$

The routine assessment of the axilla by means of ultrasound, combined with fine-needle biopsy, has reduced the rate of positive SLNBs ${ }^{19,20}$ and has enabled the identification of patients with axillary metastases who require ALND. A retrospective study of 1140 patients (T1/T2) at the Mayo Clinic in Rochester, Minnesota (all of whom were negative for axillary ultrasound and fine-needle aspiration), reported $13 \%$ of patients to be SLNB positive. Only $3 \%$ of patients had $\geq 3$ positive SLNs. ${ }^{21}$ The reported SLN positivity rate of $<20 \%$ in patients with early breast cancer in the era of mammograms raises questions about that same role for SLNB, and consequently the need for performing ALND when the SLNB is positive and the patient is receiving adjuvant treatment (radiotherapy or medical therapy).

Radiotherapy actively contributes to the success of the conservative approach. The AMAROS (Radiotherapy or Surgery of the Axilla After a Positive Sentinel Node in Breast Cancer) trial found that ALND and axillary radiotherapy after a positive SLNB finding provided excellent and comparable axillary control for patients with T1-2 primary breast cancer and no palpable lymphadenopathy, but that radiotherapy provided significantly less morbidity. ${ }^{22}$ It is recognized that whole-breast radiotherapy decreases the regional recurrence rate of tumors, most likely caused by accidental irradiation of part of the axilla. In fact, the lower part of the axilla is currently irradiated and receives a nearly therapeutic dose, depending on the upper limit of the tangential fields to the breast or

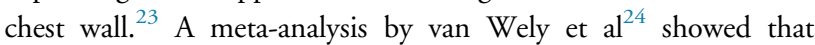
external-beam radiotherapy to the breast was associated with a lower axillary recurrence rate compared to that in patients who did not receive it as part of initial therapy. Although it may not be considered therapeutic, ${ }^{25}$ the dose delivered to the region in which the SLNs are normally found could well influence the natural evolution of residual tumor cells.

The presence of lymph node metastases does not necessarily imply a further clinically evident development of the disease. The National Surgical Adjuvant Breast and Bowel Project (NSABP) B-04 trial demonstrated that less than half of the patients with occult nodal metastases developed clinically detectable lymph nodes. None of the patients received adjuvant systemic therapy. ${ }^{26}$ Systemic therapy plays a key role in achieving low regional recurrence rates. 
Adjuvant systemic therapy significantly reduces locoregional recurrence, ${ }^{27-29}$ and neoadjuvant medical therapy can eradicate axillary lymph node metastases. ${ }^{30}$

The subtypes may be predictive of locoregional recurrence and survival even after postmastectomy radiotherapy and neoadjuvant chemotherapy. ${ }^{31-33}$ In a meta-analysis conducted by Lowery et $\mathrm{al}^{34}$ locoregional recurrence rates varied between different subtypes. In particular, luminal tumors exhibited the lowest rates of local recurrence. Patients with triple-negative and HER-2/neu-overexpressing breast tumors were at increased risk of developing local recurrence after conservative surgery or mastectomy. Furthermore, several studies have suggested that the triplenegative tumor subtype may predict a lower risk of nodal involvement. ${ }^{35-39}$ Because biology and systemic therapy influence the natural evolution of disease, the indications for axillary surgery should take these factors into consideration.

Single-center studies do not demonstrate any benefits in performing axillary surgery, but meta-analyses lead to a different conclusion. A recent meta-analysis shows an advantage of axillary surgery both for overall survival and recurrence-free survival. ${ }^{40}$ It was conducted on patients with operable primary breast cancer to determine the clinical impact of ALND in the treatment of invasive breast cancer. ALND seems to positively affect overall and recurrence-free survival from breast cancer.

Another meta-analysis concluded that for patients with micrometastasis at SLN, SLNB alone is noninferior to completion ALND. For patients with macrometastases to the axilla, omitting ALND may also be considered a feasible option, provided that the patients receive appropriate systemic chemotherapy and hormone therapy. However, this should be considered with caution because this meta-analysis had a smaller number of patients with a macrometastatic sentinel node. ${ }^{41}$

A large review conducted on patients with 1 to 2 metastatic lymph nodes who underwent SLNB or ALND showed an increase of breast cancer-specific survival limited to patients younger than 50 years old with hormone receptor-negative tumors who underwent ALND. ${ }^{42}$ It seems that only some subgroups of patients draw benefit from ALND, not the entire population.

\section{Conclusion}

The real advantage of axillary surgery in patients who are undergoing conservative surgery with whole-breast radiotherapy appears limited to those with $>2$ metastatic lymph nodes (ie, only $4.3 \%$ of $\mathrm{T} 1$ tumor cases, according to our data).

Currently ongoing trials such as SOUND and INSEMA, because they are conducted on the entire population of early breast cancers, may lack a sufficient number of events and consequently will demonstrate the noninferiority in avoiding ALND. By considering the other emerging factors ${ }^{42,43}$ that influence survival after ALND in breast carcinoma, such studies should investigate specific subgroups, not the entire population of patients.

\section{Clinical Practice Points}

- This study retrospectively investigated the real incidence of early breast cancers (treated with conservative surgery plus radiotherapy) presenting $>2$ metastatic lymph nodes after axillary surgery.
- The role of axillary lymph node surgery is under investigation because SLNB is sufficient to stage the disease.

- Axillary surgery is burdened with complications that affect quality of life.

- Recent studies have demonstrated that ALND might be safely avoided if SLNB presents $\leq 2$ positive lymph nodes.

- The real advantage of axillary surgery seems to be limited only to a specific subgroup of T1 patients who are undergoing conservative surgery plus radiotherapy.

- The role of SLNB is under investigation; ongoing trials have demonstrated the noninferiority of omitting this procedure. However, these trials are directed to the entire population and thus will likely confirm this hypothesis.

- We think that these studies should be conducted for specific subgroups of patients (according to the biology of the tumor and other emerging factors that affect tumor behavior) to determine who will receive benefit from axillary dissection.

\section{Acknowledgment}

We thank Russell Edu Samuel William for English-language editing.

\section{Disclosure}

The authors have stated that they have no conflict of interest.

\section{References}

1. Giuliano AE, McCall L, Beitsch P, et al. Locoregional recurrence after sentinel lymph node dissection with or without axillary dissection in patients with sentinel lymph node metastases: the American College of Surgeons Oncology Group Z0011 randomized trial. Ann Surg 2010; 252:426-32.

2. Galimberti V, Cole BF, Zurrida S, et al. Axillary dissection versus no axillary dissection in patients with sentinel-node micrometastases (IBCSG 23-01): a phase 3 randomised controlled trial. Lancet Oncol 2013; 14:297-305.

3. Agresti R, Martelli G, Sandri M, et al. Axillary lymph node dissection versus no dissection in patients with T1N0 breast cancer: a randomized clinical trial INT09/98. Cancer 2014; 120:885-93.

4. Lyman GH, Temin S, Edge SB, et al. Sentinel lymph node biopsy for patients with early-stage breast cancer: ASCO clinical practice guideline update. J Clin Oncol 2014; 32:1365-83

5. Coates AS, Winer EP, Goldhirsch A, et al. Tailoring therapies-improving the management of early breast cancer: St Gallen International Expert Consensus on the Primary Therapy of Early Breast Cancer 2015. Ann Oncol 2015; 26:1533-46.

6. Gentilini $\mathrm{O}$, Veronesi U. Abandoning sentinel lymph node biopsy in early breast cancer? A new trial in progress at the European Institute of Oncology of Milan (SOUND: Sentinel node vs. Observation after axillary UltraSouND). Breast 2012; 21:678-81.

7. Reimer T, Hartmann S, Stachs A, Gerber B. Local treatment of the axilla in early breast cancer: concepts from the national surgical adjuvant breast and bowel project B-04 to the planned intergroup sentinel mamma trial. Breast Care 2014; 9:87-95.

8. Marrazzo A, Taormina P, Noto A, et al. Localization of the sentinel node in breast cancer: prospective comparison of vital staining and radioactive tracing methods. Chir Ital 2004; 56:621-7.

9. Marrazzo A, Taormina P, Gebbia V, et al. Is sentinel lymph node biopsy more accurate than axillary dissection for staging nodal involvement in breast cancer patients? Chir Ital 2007; 59:693-9.

10. Lucci A, McCall LM, Beitsch PD, et al. Surgical complications associated with sentinel lymph node dissection (SLND) plus axillary lymph node dissection compared with SLND alone in the American College of Surgeons Oncology Group Trial Z0011. J Clin Oncol 2007; 25:3657-63.

11. Marrazzo A, Taormina P, David M, et al. Surgical treatment of breast cancer in day surgery. Chir Ital 2007; 59:687-91.

12. Marrazzo A, Taormina P, Marrazzo E, et al. The sentinel node biopsy is not contraindicated in multifocal breast carcinoma. Eur J Oncol 2011; 16:105-10.

13. Marrazzo A, Palumbo VD, Marrazzo E, et al. Localization of sentinel lymph node in breast cancer. A prospective study. Int J Surg 2014; 12:162-4.

14. Mansel RE, Fallowfield L, Kissin M, et al. Randomized multicenter trial of sentinel node biopsy versus standard axillary treatment in operable breast cancer: the ALMANAC trial. J Natl Cancer Inst 2006; 98:599-609.

15. Fleissig A, Fallowfield LJ, Langridge CI, et al. Post-operative arm morbidity and quality of life: results of the ALMANAC randomised trial comparing sentinel node 
biopsy with standard axillary treatment in the management of patients with early breast cancer. Breast Cancer Res Treat 2006; 95:279-93.

16. Goyal A, Newcombe RG, Chhabra A, et al. Factors affecting failed localisation and false- negative rates of sentinel node biopsy in breast cancer: results of the ALMANAC validation phase. Breast Cancer Res Treat 2006; 99:203-8.

17. Dengel LT, Van Zee KJ, King TA, et al. Axillary dissection can be avoided in the majority of clinically node negative patients undergoing breast-conserving therapy. Ann Surg Oncol 2014; 21:22-7.

18. Gentilini O, Botteri E, Dadda P, et al. Physical function of the upper limb after breast cancer surgery. Results from the SOUND (Sentinel node vs. Observation after axillary Ultra-souND) trial. Eur J Surg Oncol 2016; 42:685-9.

19. Diepstraten SC, Sever AR, Buckens CF, et al. Value of preoperative ultrasoundguided axillary lymph node biopsy for preventing completion axillary lymph node dissection in breast cancer: a systematic review and meta-analysis. Ann Surg Oncol 2014; 21:51-9.

20. Houssami N, Ciatto S, Turner RM, et al. Preoperative ultrasound-guided needle biopsy of axillary nodes in invasive breast cancer: meta-analysis of its accuracy and utility in staging the axilla. Ann Surg 2011; 254:243-51.

21. Ibrahim-Zada I, Grant CS, Glazebrook KN, Boughey JC. Preoperative axillary ultrasound in breast cancer: safely avoiding frozen section of sentinel lymph nodes in breast-conserving surgery. J Am Coll Surg 2013; 217:7-15.

22. Donker M, van Tienhoven G, Straver ME, et al. Radiotherapy or surgery of the axilla after a positive sentinel node in breast cancer (EORTC 10981-22023 AMAROS): a randomised, multicentre, open-label, phase 3 non-inferiority trial. Lancet Oncol 2014; 15:1303-10.

23. Belkacemi Y, Allab-Pan Q, Bigorie V, et al. The standard tangential fields used for breast irradiation do not allow optimal coverage and dose distribution in axillary levels I-II and the sentinel node area. Ann Oncol 2013; 24:2023-8.

24. van Wely BJ, Teerenstra S, Schinagl DA, et al. Systematic review of the effect of external beam radiation therapy to the breast on axillary recurrence after negative sentinel lymph node biopsy. Br J Surg 2011; 98:326-33.

25. Kataria T, Bisht SS, Gupta D, et al. Incidental radiation to axilla in early breast cancer treated with intensity modulated tangents and comparison with conventional and 3D conformal tangents. Breast 2013; 22:1125-9.

26. Fisher B, Jeong JH, Anderson S, et al. Twenty-five-year follow-up of a randomized trial comparing radical mastectomy, total mastectomy, and total mastectomy followed by irradiation. N Engl J Med 2002; 347:567-75.

27. Fisher B, Dignam J, Bryant J, et al. Five versus more than five years of tamoxifen therapy for breast cancer patients with negative lymph nodes and estrogen receptor positive tumors. J Natl Cancer Inst 1996; 88:1529-42.

28. Fisher B, Dignam J, Mamounas EP, et al. Sequential methotrexate and fluorouracil for the treatment of node-negative breast cancer patients with estrogen receptor-negative tumors: eight-year results from National Surgical Adjuvant Breast and Bowel Project (NSABP) B-13 and first report of findings from NSABP B-19 comparing methotrexate and fluorouracil with conventional cyclophosphamide, methotrexate, and fluorouracil. I Clin Oncol 1996; 14: 1982-92.
29. Romond EH, Perez EA, Bryant J, et al. Trastuzumab plus adjuvant chemotherapy for operable HER2-positive breast cancer. N Engl J Med 2005; 353:1673-84.

30. Rouzier R, Extra JM, Klijanienko J, et al. Incidence and prognostic significance of complete axillary downstaging after primary chemotherapy in breast cancer patients with T1 to T3 tumors and cytologically proven axillary metastatic lymph nodes. J Clin Oncol 2002; 20:1304-10.

31. Kyndi M, Sørensen FB, Knudsen H, et al. Estrogen receptor, progesterone receptor, HER-2, and response to postmastectomy radiotherapy in high-risk breast cancer: the Danish breast. I Clin Oncol 2008; 26:1419-26.

32. Meyers MO, Klauber-Demore N, Ollila DW, et al. Impact of breast cancer molecular subtypes on locoregional recurrence in patients treated with neoadjuvant chemotherapy for locally advanced breast cancer. Ann Surg Oncol 2011; 18:2851-7.

33. Caudle AS, Yu TK, Tucker SL, et al. Local-regional control according to surrogate markers of breast cancer subtypes and response to neoadjuvant chemotherapy in breast cancer patients undergoing breast conserving therapy. Breast Cancer Res 2012; 14:R83.

34. Lowery AJ, Kell MR, Glynn RW, et al. Locoregional recurrence after breast cance surgery: a systematic review by receptor phenotype. Breast Cancer Res Treat 2012 133:831-41.

35. Marrazzo A, Boscaino G, Marrazzo E, et al. Breast cancer subtypes can be deter minant in the decision making process to avoid surgical axillary staging: a retrospective cohort study. Int J Surg 2015; 21:156-61.

36. Crabb SJ, Cheang MC, Leung S, et al. Basal breast cancer molecular subtype predicts for lower incidence of axillary lymph node metastases in primary breast cancer. Clin Breast Cancer 2008; 8:249-56.

37. Van Calster B, Vanden Bempt I, Drijkoningen M, et al. Axillary lymph node status of operable breast cancers by combined steroid receptor and HER-2 status: triple positive tumours are more likely lymph node positive. Breast Cancer Res Treat 2009; 113:181e187.

38. Kim MJ, Ro JY, Ahn SH, Kim HH, Kim SB, Gong G. Clinicopathologic sig nificance of the basal-like subtype of breast cancer: a comparison with hormone receptor and Her2/neu-overexpressing phenotypes. Hum Pathol 2006; 37:1217-26.

39. Reyal F, Rouzier R, Depont-Hazelzet B, et al. The molecular subtype classification is a determinant of sentinel node positivity in early breast carcinoma. PLoS One 2011; 6:e20297.

40. Joyce DP, Manning A, Carter A, et al. Meta-analysis to determine the clinical impact of axillary lymph node dissection in the treatment of invasive breast cancer. Breast Cancer Res Treat 2015; 153:235.

41. Ram R, Singh J, Mc Caig E. Sentinel node biopsy alone versus completion axillary node dissection in node positive breast cancer: systematic review and meta-analysis. Int J Breast Cancer 2014; 2014:513780.

42. Li S, Liu F, Chen K, et al. The extent of axillary surgery is associated with breast cancer-specific survival in T1-2 breast cancer patients with 1 or 2 positive lymph nodes: a SEER-population study. Medicine 2016; 95 :e3254.

43. Toshikawa C, Koyama Y, Nagahashi M, et al. Predictive factors for non-sentine lymph node metastasis in the case of positive sentinel lymph node metastasis in two or fewer nodes in breast cancer. J Clin Med Res 2015; 7:620-6. 